\title{
EKSISTENSI KAUM TERTAHBIS dalam Perspektif Ignasius dari Antiokia, Yohanes Krisostomus, Origenes dan Ambrosius dari Milan
}

\author{
Sihol Situmorang* \\ Program Studi Ilmu Filsafat, Fakultas Filsafat, Unika Santo Thomas \\ Email: fransit@yahoo.com
}

\begin{abstract}
Abstrak
Dalam Gereja Katolik, keberadaan dan peran kaum tertahbis (diakon, imam, uskup) termasuk sesuatu yang sangat essensial dan fundamental. Pemahaman akan eksistensi dan hakikat imamat khusus ini mesti didasarkan pada Kitab Suci, khususnya Perjanjian Baru dalam konteks pelayanan terhadap komunitas Kristen dan karya missioner Gereja yang begitu pesat. Para Bapa Apostolik mulai merefleksikan pendekatan tipologis atas imamat Perjanjian Lama untuk berbicara tentang imamat pelayan Perjanjian Baru. Konsep imamat kaum tertahbis pun semakin bercorak hirarkis. Para Bapa Gereja (Ignasius dari Antiokia, Yohanes Krisostomus, Origenes dan Ambrosius dari Milan) mengajak kaum tertahbis, sebagai alter Christus, untuk menghayati imamat Kristus yang tunggal dan lestari.
\end{abstract}

Kata-kata kunci: Gereja, hirarki, imamat, komunitas, pelayan, eksistensi, Ignasius, Yohanes Kristostomus, Origenes, Ambrosius.

\section{Pengantar}

Salah satu alasan tentang pentingnya mendalami pemikiran Bapabapa Gereja adalah tercapainya sejumlah rumusan dasariah doktrin Gereja di masa mereka. Mereka merupakan saksi istimewa Tradisi. ${ }^{1}$ Dalam pidato pembukaan KV II (11 Oktober 1962), Paus Yohanes XXIII berkata bahwa tatapan ke masa lampau adalah stimulus guna meneruskan karunia iman secara kreatif. Paus yang digelari Papa Buono ini memilih Gregorius Nazianze, Yohanes Krisostomus dan Gregorius Agung sebagai

\footnotetext{
*Sihol Situmorang, lisensiat dalam bidang Teologi Patristik; lulusan Universitas Lateranensis, Roma; dosen Teologi pada Fakultas Filsafat Unika St. Thomas, Sumatera Utara.

${ }^{1}$ Congregation for Catholic Education, Instruction on the Study of the Fathers of the Church in the Formation of Priests, no 17-18, (Rome: tanpa penerbit, 1989), hlm. 11.
} 
pelindung Konsili Vatikan II. ${ }^{2}$ Dalam Ensiklik Evangelii Nuntiandi Paus Paulus VI menegaskan bahwa untuk mencapai perkembangan kita mesti belajar dari pengalaman awal Gereja. ${ }^{3}$ Menurut Yohanes Paulus II, pembaruan di bidang teologi, pastoral dan spiritualitas dicapai dengan bercermin kepada para Bapa Gereja. ${ }^{4}$ Pentingnya mengenal alam pikiran kaum tertahbis, sebagai insan bagi YANG LAIN dan untuk yang lain, pelayan sabda dan sakramen. Kaum tertahbis masa kini, sebagaimana pada awal kekristenan, dipanggil untuk menghayati imamat Kristus yang tunggal dan lestari dan menjadikan diri mereka sebagai gambaran yang hidup dan jelas atas pribadi Kristus, Sang Gembala Baik. ${ }^{5}$

\section{Pelayan Jemaat dalam Tradisi Kristianitas}

\section{Perjanjian Baru}

Komunitas kristen perdana memahami jati dirinya sebagai Israel baru, umat Perjanjian Baru dan pewaris janji ilahi (bdk.1Ptr 2,10; Kis 15:14; Gal 3:29; 4:29; 6:16; Rom 9:1-13; 9:25; 1Kor 1:1; 10:18.32; 2 Kor $6: 16$; 1Tes 2:14; 2Tes 1:4). Sebagai Israel Baru, Gereja juga memandang Kitab Suci sebagai miliknya dan karena itu berhak menafsirkannya. Bukan tanpa kesadaran konkrit bahwa tulisan-tulisan Perjanjian Baru tidak menggunakan atribut sacerdos bagi para pelayan komunitas. Di kalangan orang Yahudi dan kaum kafir, seorang imam, yang dipilih dari keluarga atau kasta tertentu dan terikat pada suatu tempat ibadah, adalah perantara antara yang ilahi dan manusia. Sementara itu pelayan kristiani dipilih oleh umat dan dinamai pelayan rahasia Allah (1Kor 4:1; 2 Kor 2:14; Rom 12:1; 1Ptr 2:4-6). Dalam jemaat Kristen perdana terdapat jabatan rasul, penatua episcopus dan diakonos (Flp 1:1; Kis 6-8; Kis 14:23; Tit 1:5). Jabatan itu tidak menuntut karakter sacer khusus, sebab seluruh umat adalah kudus, bangsa terpilih, milik Allah, imamat rajawi

\footnotetext{
${ }^{2}$ Luigi Padovese, I sacerdoti dei primi secoli, Testimonianze dei Padri sui ministeri ordinati, (Roma: Laurentianum, 1992), hlm. 2.

${ }^{3}$ Paolo VI, Esortazione Apostolica Evangelii Nuntiandi 73, (Enchridion Vaticanum V, 1976), hlm. 1103.

${ }^{4}$ John Paul II, Epistola Apostolica Patres Ecclesiae 6, Enchridion Vaticanum VII, 1980), hlm. 38.

${ }^{5}$ Yohanes Paulus II, Anjuran Apostolik Pastores Dabo Vobis no. 5, (Seri Dokumen Gerejawi no. 25), diterjemahkan oleh R. Hardawiryana (Jakarta: DokPen KWI, 1992), hlm. 15-16.
} 
(1Ptr 2:9). Dengan itu skema pemikiran piramidal yang lazim di kalangan Yahudi dan kafir, di mana clerus berada di puncak, disingkirkan. ${ }^{6}$

Surat Ibrani, yang sering dijadikan dasar teologi imamat, memakai istilah imam hanya untuk Kristus, imam abadi (Ibr 4:14-5:10). Petrus menyebut orang yang telah dibaptis sebagai bangsa terpilih dan imamat rajani yang mempersembahkan korban rohani kepada Allah dan memberitakan perbuatan-perbuatan-Nya yang besar (1Ptr 2:5-9). Paulus menyebut dirinya pelayan Yesus Kristus di antara orang bukan Yahudi dalam pemberitaan Injil Allah supaya mereka menjadi persembahan yang berkenan dan dikuduskan oleh Roh Kudus (Rom 15:16). ${ }^{7}$

\section{Bapak-Bapak Apostolik}

Akhir abad I sampai abad II, dalam Gereja mengemuka ide mengenai kesatuan sebagai umat pilihan, imamat rajawi, bangsa yang kudus. Ketika berbicara tentang pelayan, Didaché, Klemens dan Ignasius tidak mempersoalkan perbedaan peran. Para nabi, pengajar, uskup dan diakon menjalankan pelayanannya sesuai dengan aturan, tempat dan karisma masing-masing dalam lingkup tubuh yang sama, di mana Kristus adalah kepala. ${ }^{8}$ Kesatuan lebih penting daripada pelayanan personal. ${ }^{9}$

\footnotetext{
${ }^{6}$ Vittorino Grossi dan Angelo Di Berardino, La Chiesa antica: ecclesiologia e istiturioni, (Roma: Borla, tanpa tahun), hlm. 77-79; Luigi Padovese, I sacerdoti dei primi secoli, ..., hlm. 12-16.

${ }^{7}$ Vittorino Grossi - Angelo Di Berardino, La Chiesa antica ..., hlm. 80.

${ }^{8}$ Didaché 15,1-2, "Pilihlah bagimu, uskup (pengawas) dan diakon (pelayan) yang layak bagi Tuhan, yakni: laki-laki yang lembut hati, tidak tamak [tidak melekat pada uang], jujur dan teruji. Sebab mereka juga mengadakan bagimu liturgi [pelayanan umum] seperti para nabi dan pengajar. Janganlah memandang rendah mereka, sebab mereka adalah orang-orang terhormat di antara kamu, bersama-sama dengan para nabi dan pengajar." [Lihat Kitab Didache (diterjemahkan oleh Christian P. Sidenden, John Simon Adam dan Dimitri Nugrahadi), (Jakarta: Synaxis Press, 2006), hlm. 50-51].

${ }^{9}$ Ide tentang misi dan kesatuan misalnya tampak dalam Doa Ekaristi Didaché 9,4, "Roti yang dipecah-pecah ini seperti butiran gandum yang terpencar-pencar di atas pebukitan dan pada waktu panen dikumpulkan bersama kembali menjadi satu; maka biarlah juga Gereja-Mu dikumpulkan bersama kembali dari segenap ujung bumi ke dalam Kerajaan-Mu" [Lihat Kitab Didache, hlm. 44]; Didaché 10,5, "Ya Tuhan, ingatlah akan Gereja-Mu. Jadikanlah sempurna di dalam kasih-Mu, kumpulkanlah dari empat penjuru mata angin, sucikanlah bagi Kerjaan-Mu yang kudus yang telah Engkau sediakan baginya" [Lihat Kitab Didache, hlm. 45]. Dalam Lettera ai Corinzi 59,4, Clemens menulis. "Agar segala bangsa mengenal Engkau, satu-satunya Allah, dan bahwa Yesus Kristus adalah Putera-Mu dan kami adalah umat-Mu dan kawanan domba-Mu" [Lihat Enrico dal Covolo, Sacerdoti come i nostri Padri, I Padri della Chiesa maestri di formazione sacerdotale, (Roma: Editrice Rogate, 1998), hlm. 65].
} 
Pokok perhatian adalah menghidupi identitas komunitas baru (bdk. Kis 2:41-47) dan karya misioner. ${ }^{10}$

Akhir abad II sampai abad III keadaan di dalam Gereja mulai berubah seiring dengan situasi politik yang relatif aman dan kondusif untuk konsolidasi struktur Gereja. Konsep imamat kaum tertahbis semakin bercorak hirarkis. Secara sosiologis clerus dibedakan dari laicus, kendati kesadaran bahwa pelayan tertahbis berasal dari awam tidak memudar. Imamat kaum beriman juga tetap menjadi ciri khas umat Allah. Pada periode ini menonjol dialektika harmonis antara kesatuan umat terpilih yang kudus dengan struktur hirarkis Gereja. ${ }^{11}$

Para Bapa Apostolik mulai merefleksikan pendekatan tipologis atas imamat Perjanjian Lama untuk berbicara tentang imamat pelayan Perjanjian Baru. Dalam Didachè 13,3;14, para pelayan baru dibandingkan dengan imam Perjanjian Lama dan ekaristi disebut kurban. Surat Pertama Klemens dan Surat Ignasius dari Antiokia kepada umat di Magnesia 7,2 menyebut Yesus imam agung. Dalam Apologia I,65-67 dan Dialog 41,1-3;117,4, Yustinus berbicara tentang pemimpin perayaan ekaristi. Ekaristi dilihat sebagai realisasi nubuat Maleaki tentang kurban kudus. Ireneus, dalam Adversus Haereses V,34,3, menerapkan istilah teknis imam (sacerdos) kepada Yesus, dan semua orang kristen disebut sacerdotes. ${ }^{12}$

\section{Abad III-IV}

Sejak abad III, istilah imam (hiereus-sacerdos; archiereus-summus sacerdos) dipakai secara meluas, khususnya untuk menyebut uskup. Sacerdos menjadi sinonim dari episcopus; jarang untuk presbyter. Presbyter disebut imam tingkat kedua. Tertullianus adalah pengarang pertama yang memakai istilah imam untuk pelayan Gereja. Uskup disebut sacerdos/summus sacerdos, dan presbyter tidak disebut secara langsung. Pada masa ini, clerus mulai dibedakan dari laicus. Origenes menyebut uskup sebagai sacerdos par exellence, dan presbyter sebagai

\footnotetext{
${ }^{10}$ Enrico dal Covolo, Sacerdoti come i nostri Padri,... hlm. 60-65; Luigi Padovese, I sacerdoti dei primi secoli, ..., hlm. 23-30.

${ }^{11}$ Enrico dal Covolo, Sacerdoti come i nostri Padri ..., hlm. 65-72.

12 Vittorino Grossi - Angelo Di Berardino, La Chiesa antica ..., hlm. 80-81.
} 
sacerdos inferioris ordinis. ${ }^{13}$ Awal abad IV, dalam Codex Theodosianus 16,2,2, Konstantinus menulis, "Qui divino cultui ministeria impediunt, id est qui clerici appellantur." Konsili Kartago 348, dalam Codex Theodosianus Kan. 6, menyatakan, "Qui serviunt Deo et annexit sunt clero." Akhir abad IV, khusus di Timur (Yohanes Chrisostomus, Theodorus Mopsuestia dan Konstitusi Apostolik), istilah imam semakin sering digunakan baik untuk uskup maupun presbyter mungkin karena jumlah komunitas yang semakin berkembang sampai ke desa-desa. Para imam (presbyter) melaksanakan hampir semua tugas yang dulunya diemban oleh uskup, seperti merayakan ekaristi, mengajar dan memimpin umat. $^{14}$

Supremasi agama Kristen dalam Kekaisaran Romawi terjadi tahun 380. Gereja dituntut semakin mengorganisir struktur internal, hirarki dan formasi pelayan suci. Tradisi Romawi mengkategorikan masyarakat atas dasar stratifikasi sosial-politik, professi dan religius. Ordo (pemimpin) memiliki kehormatan (honor) dan martabat (dignitas) lebih tinggi dibandingkan plebs (rakyat biasa). ${ }^{15}$ Sejak Konstantinus jarak antara plebs (umat biasa/laicus) dengan ordo/ clerus makin lebar. Menyerupai otoritas sipil, uskup menerima lencana pejabat negara seperti pallium dan kasut. ${ }^{16}$ Juga diciptakan tanda-tanda baru dan pakaian khusus bukan hanya untuk tugas liturgi, tetapi juga dalam hidup sehari-hari untuk membedakan clerus dari awam. ${ }^{17}$

\footnotetext{
${ }^{13}$ Dalam Traditio Apostolica 3, seputar doa penahbisan uskup tercatat: "Bapa, yang mengenal hati umat manusia, anugerahkanlah martabat imamat tertinggi kepada hamba-Mu yang telah Engkau pilih untuk jabatan uskup, untuk menggembalakan kawanan-Mu yang kudus, untuk menjalankan tugas secara sempurna dan demi nama-Mu, untuk menjadi pelayan-Mu siang dan malam,... untuk mempersembahkan kepada-Mu pemberian Gereja-Mu yang kudus, untuk memiliki, dalam bimbingan Roh Imam Agung, kuasa mengampuni dosa seturut perintah-Mu, dan untuk membagi-bagikan tugas sesuai dengan kehendak-Mu." [Lihat Enrico dal Covolo, Sacerdoti come i nostri Padri ..., hlm. 71].

${ }^{14}$ Vittorino Grossi - Angelo Di Berardino, La Chiesa antica ..., hlm. 81-82.

15 Dalam Tract. In ps. 1, Hieronymus mencatat, "in ecclesia istae (episcopus et presbyter) sunt dignitates.

16 Dalam De officiis min. 1,82, Ambrosius menghimbau klerus mengenakan pakaian dari kualitas biasa tanpa warna-warna. Paus Celestinus (428), dalam Epist. 4,1,2 menulis kepada para uskup Gallia bahwa mereka tidak dibedakan dari orang lain karena pakaian, tetapi karena ajaran.

17 Vittorino Grossi - Angelo Di Berardino, La Chiesa antica ..., hlm. 78-80; Enrico dal Covolo, Sacerdoti come i nostri Padri ..., hlm. 72-74.
} 


\section{Abad V-VII}

Di Timur, sejak abad V, Theodoretus dari Cyrrus dan Pseudo Dionisius memakai istilah hierus/sacerdos untuk presbyter; uskup disebut archiereus. Di Barat, pada abad VII, istilah sacerdos digunakan hanya bahkan menjadi sinonim presbyter. Pada masa Innocentius I (401417) dikenal clerici superioris ordinis (uskup, imam dan diakon) dan clerici inferioris ordinis (subdiakon, akolit, eksorsis, ostiarius, lektor). ${ }^{18}$

\section{Pengaruh Paganisme dan Tradisi Yahudi dan Budaya Romawi}

Pengaruh paganisme, tradisi piramidal masyarakat Romawi, dan Perjanjian Lama yang membedakan kasta para imam dengan rakyat jelata, mulai masuk dalam Gereja. Dua instansi yang saling melengkapi (imamat umum-struktur karismatis dan sakramen tahbisan-struktur hirarkis) dicermati. Organisasi yang lebih efektif seperti dalam Traditio Apostolica dirasa makin perlu. Penahbisan clerus (uskup, imam, diakon) dengan penumpangan tangan. Pelayan lain (pengaku iman, perawan, penyembuh, lektor, subdiakon, ostiarius dan akolit) tanpa penumpangan tangan. Uskup menduduki tempat tertinggi (pengatur, kepala, penerus para rasul, ambil bagian dalam Roh Imam Agung). Imam adalah penasihat dan pembantu uskup. Diakon ditahbisan untuk melayani uskup. ${ }^{19}$

Dicermati juga sejauh mana dalam Perjanjian Lama terdapat gagasan tentang pelayan-pelayan baru. Proses ini berpuncak pada Isidorus dari Siviglia, yang menyebut Harun sebagi model uskup, anakanaknya sebagai model para imam dan kaum levi sebagai model diakon. Kendati gagasan tentang imamat kultis Perjanjian Lama dan paganisme tidak ada kaitannya dengan imamat Perjanjian baru, namun tidak dapat dipungkiri pengaruhnya atas terciptanya pemisahan antara kasta para imam dan awam, antara clerus/ordo dengan populus/plebs. ${ }^{20}$ Pada mulanya, semua umat disebut kudus (plebs sancta), kini hanya clerus

\footnotetext{
18 Enrico dal Covolo, Sacerdoti come i nostri Padri ..., hlm. 72; Vittorino Grossi - Angelo Di Berardino, La Chiesa antica ..., hlm. 82.

${ }^{19}$ Enrico dal Covolo, Sacerdoti come i nostri Padri ..., hlm. 68-72.

${ }^{20}$ Vittorino Grossi - Angelo Di Berardino, La Chiesa antica ..., hlm. 82-83.
} 
atau ordo yang disebut sacer. Tuntutan selibat atau bertarak (akhir abad IV), tonsura dan sejumlah privilese semakin membedakan, memisahkan bahkan menjurus pada polarisasi dua kutub antara orang-orang yang dibaptis (laicus) sebagai kelompok sederhana dan hirarki kaum clerus. $^{21}$

\title{
Eksistensi Clerus
}

\section{Ignasius dari Antiokia († 107)}

Ignasius mengajak orang kristen untuk membangun kesatuan di bawah pimpinan uskup, bersama imam dan diakon dalam posisi yang lebih rendah, sebagai gambaran kesatuan ilahi. ${ }^{22}$ Dalam Surat kepada Umat di Efesus 4, Ignasius menulis:

\begin{abstract}
"Baiklah kamu tetap berjalan seiring dengan pandangan uskup seperti memang sudah kalian lakukan. Sebab imam kalian yang baik dan pantas di hadapan Allah bersatu secara harmonis dengan uskup ibarat kecapi dan senarnya. Dalam kerukunan dan kasih yang harmonis tersebut Yesus Kristuslah yang dimuliakan. Secara bersama-sama kalian menjadi paduan suara, yang secara harmonis menyanyikan sebuah lagu bagi Allah.",23
\end{abstract}

\footnotetext{
21 Vittorino Grossi - Angelo Di Berardino, La Chiesa antica ..., hlm. 83. Administrasi Romawi membedakan populus (rakyat biasa) dan ordines (pemimpin). Dalam lingkup Gereja, umat beriman disebut populus/laicus dan clerus sebagai ordo, yang memiliki bonor (kehormatan) dan dignitas (martabat) yang lebih tinggi. Dalam Tract. In ps. 1, Hieronymus menulis, "In ecclesia istae (episcopus et presbyter) sunt dignitates." Sejak masa Konstantinus, jarak antara plebs dan ordo kian melebar. Para uskup menerima lencana pejabat negara: pallium, kasut dan simbol lain, seperti paramenti (pakaian khusus) bukan hanya untuk tugas liturgi, tapi untuk membedakan clerus dari awam secara sosiologis. Ambrosius, dalam De officiis min. 1,82, menghimbau clerus untuk mengenakan pakaian tanpa warna-warna. Paus Celestinus (428), dalam Epist. 4,1,2, menulis kepada para uskup Gallia, mereka tidak dibedakan dari orang lain karena pakaian, tetapi karena ajaran.

${ }^{22}$ Menurut Ignasius, Uskup, colegio para imam dan diakon merupakan representasi Tiga Pribadi Ilahi: Bapa, colegio para rasul dan Krisus 'pelayan Allah' menurut daging. [Lihat Luigi Padovese, I sacerdoti dei primi secoli,... hlm. 47; Hubertus R. Drobner, Patrologia, (judul asli: Lehrbuch der Patrologie, traduzione italiana di Paolo Stefano Neri e Francesco Sirleto), (Casale Monferrato: Piemme) 1998, hlm. 103].

${ }^{23}$ Ignatius, "Epistle to The Ephisians" dalam Alexander Roberts - James Donaldson, Ante Nicene Fathers Vol. 1: The Apostolic Fathers with Justin Martir and Irenaeus ((Massachusset: Hendricson Publiser, 1999), hlm. 50-51.
} 
Setelah Ignasius menasihati umat di Smirne dalam Lettera ai Smirnesi 8,1 agar jangan ada yang melakukan sesuatu yang terkait dengan Gereja tanpa kehadiran Uskup, dalam Surat kepada Polikarpus 6, ia mengaku:

"Hidupku kuberikan kepada mereka yang tunduk kepada uskup, para imam dan diakon. Semoga aku mendapat bagian bersama mereka dalam Allah. Berusahalah bersama-sama, berjuanglah bersama, berjalanlah bersama, menderitalah bersama, istirahatlah bersama, bangunlah bersama-sama sebagai pelayan, teman dan hamba-hamba Allah. Berusahalah berkenan pada Dia, yang bagiNya kalian berjuang dan yang dari-Nya kalian menerima upah. Jangan di antara kalian ada yang menjadi pembelot. Kiranya pembaptisan kalian bertahan sebagai perisai, iman kalian sebagai ketopong, kasih kalian sebagai tombak dan kesabaran kalian sebagai baju jirah yang lengkap." 24

Ignasius menekankan dialektika subur dan kontinu antara struktur hirarkis dan kesatuan umat beriman dalam Kristus. Pentingnya communio dan harmoni antara umat beriman dan umat beriman dengan para gembala dijelaskan dengan analogi senar dan kecapi atau konser. Tanggung jawab khusus diakon, imam dan uskup adalah menganimasi komunitas. $^{25}$ Dalam Lettera ai Smirnesi 6,2, guru kesatuan ini menekankan bahwa tidak ada yang lebih berharga dari pada kesatuan Gereja dan umat beriman dalam iman dan kasih. Dia mengajak semua pihak agar bersatu dalam kasih. Seraya mengutip doa Yesus dalam perjamuan malam, dalam Surat kepada Umat di Magnesia 7, Ignasius menulis,

"Jadilah satu. Satu permohonan, satu jiwa, satu pengharapan dalam kasih. Datanglah kalian semua pada Yesus Kristus, satu-satunya

\footnotetext{
${ }^{24}$ Ignatius, "Epistle to Policarp" dalam Alexander Roberts - James Donaldson, Ante Nicene Fathers Vol. 1: The Apostolic Fathers with Justin Martir and Irenaeus ((Massachusset: Hendricson Publiser, 1999), hlm. 95.

${ }^{25}$ Enrico dal Covolo, Sacerdoti come i nostri Padri ..., hlm. 33-34; Benedictus XVI, Bapa-bapa Gereja, Hidup, Ajaran, dan Relevansi bagi Manusia di Zaman Kini (Judul asli: The Fathers, diterjemahkan oleh Waskito SJ), (Malang: Dioma, 2010), hlm. 24-25.
} 
bait Allah dan altar: Dialah satu-satunya yang lahir dari Bapa yang satu, tetap bersatu dengan-Nya dan kembali kepada-Nya dalam persatuan." 26

Sambil merangkum pengajaran dalam Kis 6, dalam Surat kepada Umat di Trallia 2, Ignasius menulis, "Para diakon yang dipanggil menjadi pelayan rahasia Kristus, harus mengupayakan kebaikan semua orang. Mereka bukan hanya pelayan makanan dan minuman, tetapi pelayan Gereja dan Allah. Hendaknya mereka menjaga diri dari setiap cela." 27 Diakon harus memiliki reputasi yang baik dan sudah teruji. Ia sejajar dengan martir, sebab hidupnya adalah suatu kesaksian. Dia mesti penuh dengan Roh kebijaksanaan sebagai buah intimitas dengan Tuhan. Pelayanan kasih (meja), sebagai tugas utama seorang diakon, harus bersumber dari doa. Menurut Ignasius, pelayan yang tidak dibentuk dalam dan oleh kontemplasi akan misteri-misteri suci Kristus hingga mencapai kesatuan dengan-Nya, mustahil dapat melaksanakan pelayanan kasih yang otentik, dan tindakannya sama sekali tidak membuahkan apa pun guna kemajuan Gereja. ${ }^{28}$

\section{Yohanes Krisostomus $(† 407)$}

Menurut Krisostomus, untuk bertumbuh dalam kasih sejati, umat beriman, khususnya para pelayan tertahbis, harus mengenal dan bersatu dengan Yesus. $^{29}$ Dalam hidup para imam, Yohanes Krisostomus

\footnotetext{
${ }^{26}$ Ignatius, "Epistle to The Magnesians" dalam Alexander Roberts - James Donaldson, Ante Nicene Fathers Vol. 1: The Apostolic Fathers with Justin Martir and Irenaeus ((Massachusset: Hendricson Publiser, 1999), hlm. 60.

${ }^{27}$ Ignatius, "Epistle to The Trallians" dalam Alexander Roberts - James Donaldson, Ante Nicene Fathers Vol. 1: The Apostolic Fathers with Justin Martir and Irenaeus ((Massachusset: Hendricson Publiser, 1999), hlm. 66-67.

${ }^{28}$ Enrico dal Covolo, Sacerdoti come i nostri Padri ..., hlm. 35.

29 Dalam Homili atas Injil Mateus 50,2-3, Yohanes Krisostomus menegaskan bahwa kita berjumpa dan mengenali Yesus terutama dalam diri orang miskin dan menderita. "Marilah belajar menjadi bijaksana dan menghormati Kristus sebagaimana Dia kehendaki dengan membagi kekayaan dengan orang miskin. Allah tidak membutuhkan barang-barang dari emas, tapi hati yang terbuat dari emas. Apa gunanya apabila altar-Nya penuh dengan piala dari emas sementara Dia mati kelaparan? Pertama-tama berilah makan orang-orang lapar dan dengan itu Anda menghiasi altar-Nya secara melimpah." [Enrico dal Covolo, Sacerdoti come $i$ nostri Padri ..., hlm. 37-38]. Dalam Komentar atas Injil Yohanes 46,3, Krisostomus menegaskan bahwa kesatuan dengan Yesus tidak hanya dalam cinta kasih, tetapi juga
} 
menekankan perpaduan antara doa dan teladan hidup, sebagai buah perjumpaan dengan Tuhan melalui sabda dan sakramen-sakramen. ${ }^{30}$

Dalam Dialog dengan Basilius tentang Imamat IV,3, Krisostomus menyebut teladan dan ajaran merupakan obat yang dimiliki imam, "Bagi mereka yang merawat tubuh, tersedia aneka macam obat. Bagi kita, tidak ada sarana dan cara untuk menyembuhkan selain dari teladan hidup dan ajaran."31 Baginya, imamat adalah sarana penyemangatan dan pengabdian. Fokus pelayanan adalah keperluan kawanan. Pemeliharaan kawanan adalah tanda dan bukti nyata cinta kasih pelayan kepada pemilik domba-domba. ${ }^{32}$

Dalam Dialog dengan Basilius tentang Imamat II,1, Krisostomus menjelaskan bahwa ketika Tuhan bertanya kepada Petrus apakah ia mengasihi-Nya bukan karena Tuhan ingin mengetahui jawabannya, sebab Dia mengetahui isi hati setiap orang. Juga bukan untuk menyatakan bahwa Petrus sangat mengasihi Tuhan, tetapi untuk menunjukkan betapa Ia mengasihi Gereja dan mengajarkan kepada Petrus dan kita besarnya perhatian yang harus kita buat dalam tugas penggembalaan, yang membedakan upahan dari gembala (Yoh 10,11). ${ }^{33}$

Ignasius dan Krisostomus menggarisbawahi kontemplasi dan persatuan dengan Kristus sebagai jati diri pelayan suci. Kesatuan sempurna dengan Kristus dan pengabdian total bagi kawanan merupakan satu kesatuan karakteristik konstitutif imamat, ibarat dua sisi dari satu medali. Pengabdian total bagi kawanan adalah tanda kesatuan dengan Kristus. Pengabdian itu mendorong para imam untuk segera berlari kepada Kristus satu-satunya altar dan bait Allah. ${ }^{34}$

Bapa-bapa Antiokia ini mengajak para imam agar terus-menerus mengupayakan sintese konfigurasi dengan Kristus (persatuan dengan Dia

melalui tubuh-Nya, yang diberikan sebagai tanda cinta kasih. [Enrico dal Covolo, Sacerdoti come i nostri Padri ..., hlm. 38].

${ }^{30}$ Enrico dal Covolo, Sacerdoti come i nostri Padri ..., hlm. 38.

${ }^{31}$ Dikutip dari Luigi Padovese, I sacerdoti dei primi secoli, ..., hlm. 240-241.

32 Chrysostom, "Treatise concerning The Christian Priesthood" dalam Philip Schaff (ed), Nicene and Post Nicene Fathers, Series I, Vol. 9 (Massachusset: Hendricson Publiser, 1999), hlm.64-65.

${ }^{33}$ Chrysostom, "Treatise concerning The Christian Priesthood” ..., hlm. 40.

${ }^{34}$ Enrico dal Covolo, Sacerdoti come i nostri Padri ..., hlm. 40. 
dan hidup dalam Dia) dan dedikasi kepada Gereja-Nya (misi, persatuan dengan uskup, pelayanan yang murah hati kepada komunitas dan dunia) dalam dirinya. Pelayan tertahbis diharapkan mencapai sintese antara communio dan missio, sampai masing-masing dimensi tampak melalui dimensi yang lain. Eksistensi pelayan (tertahbis) tidak pernah boleh direduksi menjadi sebatas pembagi tetapi sekaligus saksi sejati misteri Kristus dan Gereja-Nya. ${ }^{35}$

\section{Origenes $(† 254)$}

Origenes lebih tertarik bicara tentang sisi spiritual Tubuh mistik Kristus dari pada aspek lahiriahnya. Ia lebih senang mendalami hirarki kekudusan dalam kaitan dengan peziarahan menuju kesempurnaan yang dialamatkan kepada semua orang kristen, dari pada hirarki yang kelihatan. Walau berbicara juga tentang para uskup, imam dan diakon, Origenes lebih sering mendalami imamat umum dari pada imamat hirarkis. $^{36}$

Di hadapan umat beriman, hirarki yang kelihatan mesti menujukkan hirarki kekudusan yang tidak kelihatan. Tahbisan ministerial dan kekudusan harus berjalan beriringan. Apa bila imamat umum sudah menuntut kesucian dan hidup yang pantas, iman dan pengetahuan akan

\footnotetext{
${ }^{35}$ Enrico dal Covolo, Sacerdoti come i nostri Padri ..., hlm. 40.

36 Terdapat banyak tulisan Origenes mengenai pelaksanaan imamat umum. Dalam komentar atas Im 16: 2, seputar larangan Harun setelah kematian kedua anaknya untuk memasuki tempat kudus tanpa persiapan yang perlu dan tanpa pakaian keimaman, Origenes menyadarkan umat beriman bahwa mereka adalah bangsa yang terpilih, imamat yang rajani, bangsa yang kudus, umat kepunyaan Allah, yang harus mempersembahkan kepada Allah kurban pujian, kurban doa permohonan, kurban belas kasihan, kurban kemurnian, kurban keadilan dan kekudusan. Agar umat layak mepersembahkannya dengan pantas, mereka harus memakai pakaian yang murni dan mempunyai api ilahi, yang diberikan oleh Kristus sendiri. [Origene, Omelia sul Levitico 9,1. Dikutip dari Enrico dal Covolo, Sacerdoti come i nostri Padri ..., hlm. 45].

Dalam komentar atas Im 6:8-13 tentang korban bakaran yang harus tinggal di atas perapian di atas mezbah semalam-malaman sampai pagi, Origenes mengaitkannya dengan perintah Tuhan dalam Injil supaya pinggang mereka tetap berikat dan api mereka tetap menyala. Api menunjuk kepada api iman dan cahaya pengetahuan. Pinggang yang terikat (bdk. Kel 12:11) dan pakaian keimaman melambangkan kemurnian dan kepantasan hidup, sementara pelita yang tetap bernyala melambangkan iman dan pengetahuan akan Kitab Suci. Hal-hal ini merupakan syarat mutlak bagi pelaksanaan imamat umum. [Origene, Omelia sul Levitico 4,6. Dikutip dari Enrico dal Covolo, Sacerdoti come i nostri Padri ..., hlm. 46-47].
} 
Kitab Suci sebagai syarat mutlak, imamat jabatan menuntut syarat yang lebih mutlak lagi. ${ }^{37}$ Dalam Omelia sul Levitico 6, Origenes menulis,

"Para imam harus menjadikan hukum ilahi sebagai cermin untuk menguji diri apakah mereka memakai pakaian keimaman dan menjadi contoh dalam pengetahuan, sikap dan ajaran. Hanya dengan itu mereka mencapai imamat tertinggi, baik dalam nama maupun pahala. Bila tidak, mereka telah merendahkan martabatnya, kendati dari segi jabatan mereka berada di tingkat pertama." 38

Penghargaan yang tinggi atas imamat mendorong Origenes bersikap keras dan hampir radikal terhadap pelayan suci. Ia mewantiwanti mereka yang diikutsertakan dalam martabat ilahi, kepemimpinan dan pelayanan Gereja. Dalam Omelia sui Numeri 2,1, dengan hati pilu, Origenes bertanya,

"Apakah Anda yakin, para imam, yang bangga karena ambil bagian dalam jabatan imam, berperilaku sepadan dengan jabatan mereka dan melakukan semuanya yang bertautan dengan jabatan itu? Apakah Anda yakin bahwa para diakon juga bertindak sesuai dengan jabatan mereka? Andaikan mereka hidup sesuai dengan jabatan mereka mengapa masih terdengar keluh-kesah umat, 'Lihatlah uskup, imam dan diakon ini!' Bukankah hal itu terdengar karena mereka melihat para imam atau pelayan Allah tidak melakukan kewajiban mereka sesuai dengan jabatannya?"39

Origenes tidak sungkan-sungkan secara terbuka mencela kekurangan besar para imam pada masa itu. Di mata Origenes, titik lemah para imam ialah haus akan uang dan kenikmatan dunawi dan bergaya hidup borjuis. Ia mengeluh karena para imam membiarkan diri dikuasai kecemasan duniawi. Mereka menjalani hari-hari hidupnya dengan memikirkan urusan dan kepuasan duniawi dan makanan yang enak. Dalam Omelia su Isaia 7,3, Origenes berkata,

\footnotetext{
${ }^{37}$ Enrico dal Covolo, Sacerdoti come i nostri Padri ..., hlm. 44-45; Benedictus XVI, Bapa-bapa Gereja, Hidup, Ajaran,..., hlm. 55-61.

${ }^{38}$ Dikutip dari Luigi Padovese, I sacerdoti dei primi secoli ..., hlm. 81.

${ }^{39}$ Dikutip dari Enrico dal Covolo, Sacerdoti come i nostri Padri ..., hlm. 52.
} 
"Di antara kita pejabat Gereja ada yang hanya mencari kepuasan perut, agar dihormati, mengambil persembahan yang diperuntukkan bagi Gereja demi kepentingan pribadi. Mereka hanya berbicara soal perut, dan dari sana keluar semua kata-kata yang mereka ucapkan. ${ }^{40}$

Origenes mengeluhkan para imam yang jatuh dalam karierisme, arogan dan sombong. Dalam Omelia sul Libro dei Giudici 2,2, ia menulis, "Kadang dari antara kita yang berada di sekitar altar Tuhan (yang mesti menjadi contoh kerendahan hati dan cermin bagi orang lain) ada yang sangat arogan. Dari altar Tuhan berhembus aroma kesombongan yang menjijikkan." ${ }^{41}$ Dan dalam Omelia su Ezechiele 9,2, Origenes melanjutkan,

"Betapa banyak yang lupa akan kerendahan hati setelah ditahbiskan menjadi imam. Mereka seakan-akan ditahbiskan agar berhenti menjadi orang yang rendah hati. Engkau telah ditetapkan sebagai kepala, tetapi janganlah meninggikan diri. Engkau harus tetap memandang dirimu sebagai satu di antara kawananmu, rendah hati dan menjauhkan kesombongan, puncak segala kejahatan." ${ }^{, 2}$

Dosa lain para imam menurut Origenes ialah menghina atau kurang menghormati orang kecil dan miskin, berlaku keras dan kasar, kurang sabar dan gaya hidup datar (dingin). Untuk menapaki jalan sebagai imam, Origenes menekankan pentingnya merenungkan sabda Tuhan-sebagai pelita yang bernyala, pinggang yang berikat dan mengenakan kesucian dan hidup yang pantas sebagai jubah. Dari pelayan tertahbis dituntut ketaatan radikal kepada Tuhan dan sabda-Nya, menjauhkan diri dari roh duniawi, membangun persaudaraan sejati dengan umat Allah dan memberi diri seutuhnya dalam pelayanan. ${ }^{43}$

\footnotetext{
${ }^{40}$ Dikutip dari Enrico dal Covolo, Sacerdoti come i nostri Padri ..., hlm. 52-53.

${ }^{41}$ Dikutip dari Enrico dal Covolo, Sacerdoti come i nostri Padri ..., hlm. 53.

42 Dikutip dari Enrico dal Covolo, Sacerdoti come i nostri Padri ..., hlm. 53.

${ }^{43}$ Enrico dal Covolo, Sacerdoti come i nostri Padri ..., hlm. 53.
} 
Puncak perjalanan menuju kesempurnaan adalah kemartiran di mana hirarki kekudusan dan pelayanan bersatu padu. Dalam Omelia sul Levitico 9,9, Origenes berbicara perihal api untuk kurban, lambang iman dan pengetahuan akan Kitab Suci, yang tak pernah boleh padam di atas altar dia yang memegang jabatan imam. ${ }^{44}$

Kendati mengaitkan hirarki ministerial dengan hirarki kesempurnaan, di mata Origenes imam bukanlah malaikat, tetapi seorang yang dalam hidup sehari-hari berjuang melawan dosa dan kejahatan. Usaha untuk menjauhkan diri dari dunia tidak sama dengan mencari suatu tempat yang terpisah dari dunia. Dalam Omelia sul Levitico 12,4, Origens berkata,

"Tempat kudus tidak ditemukan di suatu lokasi, tetapi dalam tindakan, dalam hidup dan dalam apa yang kita lakukan. Jika kita menuruti perintah Allah dan melayani Sabda-Nya entah di rumah, di tanah lapang atau di teater, kita berada di tempat kudus." 45

\section{Ambrosius († 397)}

Menurut Ambrosius, Kristus adalah Levi sejati yang secara khusus menganugerahkan imamat-Nya kepada imam. Sebagai gambaran Kristus, imam bertugas memperlihatkan wajah Kristus dan memberikan nyawa-Nya demi umat. Mereka harus mengasihi, meniru dan hidup sebagai milik Kristus. Dengan tak kenal lelah, imam berjuang mengalahkan diri dan dunia ini supaya sepenuhnya menjadi milik Allah, sebagaimana Kristus adalah milik Allah. ${ }^{46}$

Cinta dan intimitas pada Ekaristi, kerendahan hati, ketaatan kepada uskup, kemurnian sempurna dan persembahan diri adalah buah kasih para imam kepada Kristus. Seorang imam adalah insan yang dibaktikan dan

\footnotetext{
44 Origene, Omelia sul Levitico 9,9, "Dalam diri kita masing-masing, kita mempunyai bukan hanya api, tetapi juga kurban bakaran dan dari kurban kita altar mulai bernyala, agar bernyala selamanya. Dan aku, bila aku menyangkal semua yang kumiliki dan mengangkat salibku dan mengikuti Kristus, aku menyerahkan tubuhku untuk dibakar dan mempunyai kasih dan mencapai kemuliaan kemartiran. Aku mempersembahkan kurban bakaranku di atas altar Allah." [Dikutip dari Enrico dal Covolo, Sacerdoti come i nostri Padri ..., hlm. 54.]

${ }^{45}$ Dikutip dari Enrico dal Covolo, Sacerdoti come i nostri Padri ..., hlm. 55-56.

${ }^{46}$ Enrico dal Covolo, Sacerdoti come i nostri Padri ..., hlm. 12.
} 
dikuduskan untuk Gereja. Imamat adalah simbol pemberian diri total. Imam bukanlah seorang malaikat, tetapi seorang kristiani yang memiliki keutamaan manusiawi. Ia dipanggil untuk mempraktekkan nasihatnasihat Injil. $^{47}$

Seorang imam menguduskan diri melalui latihan rohani. Dengan murah hati dan rajin, ia melayani Ekaristi dan Sabda Allah. Fokus perjuangannya adalah keselamatan jiwa-jiwa. Seluruh waktu dan kekuatan fisiknya dicurahkan bagi pelayanan pastoral, tidak hanya sebatas kultus/ritus tapi meliputi karya cinta kasih yang tampak dalam hidup miskin dan ugahari. ${ }^{48}$ Imamat terwujud terutama lewat hidup para imam. Hidup (esse) lebih penting dari pada bicara (dire). Doa dan kasih menggantikan kata-kata. Doa dan pelayanan adalah unsur karakteristik fundamental imamat. Imam adalah man of God, man for others dan man of the Church. ${ }^{49}$

Agustinus bersaksi, bila Ambrosius kebetulan (sangat jarang) tak sedang bersama umat, dia mengisi jiwanya dengan membaca Kitab Suci; matanya terbuka, mulutnya tetap terkatup. Membaca halaman demi halaman Kitab Suci dengan mulut tertutup, bagi Agustinus, adalah bukti pengetahuan dan pemahaman luar biasa Ambrosius atas Kitab Suci. Seorang pewarta iman, harus menjadi seperti murid yang dikasihi Yesus, yang menyadarkan kepalanya dekat hati Gurunya dan belajar di situ bagaimana ia harus berpikir, berbicara dan berbuat. Sekitar uskupnya, Gereja Milan teguh dalam iman dan bersatu padu sebagai satu tubuh. ${ }^{50}$

\footnotetext{
${ }^{47}$ Enrico dal Covolo, Sacerdoti come i nostri Padri ..., hlm. 12.

${ }^{48}$ Enrico dal Covolo, Sacerdoti come i nostri Padri ..., hlm. 12-13.

${ }^{49}$ Enrico dal Covolo, Sacerdoti come i nostri Padri ..., hlm. 15.

${ }^{50}$ Enrico dal Covolo, Sacerdoti come $i$ nostri Padri ..., hlm. 14. Benedictus XVI, Bapa-bapa Gereja, Hidup, Ajaran,..., hlm. 179-180. Dalam Confessiones 9,7, Agustinus memberi informasi perihal Kaisar Valentinianus dan ibunya Yustina tahun 386 mendesak supaya sebuah Gereja diberikan untuk kelompok arian. Di dalam gereja itu, umat berkumpul dan menyatakan kesiapan untuk mati bersama sang uskup, "Kendati secara rohani masih suam-suam kuku, kami ambil bagian dalam gerakan semua umat."
} 


\section{Kesimpulan}

Dalam tradisi Kristen, pelayan umat merupakan panggilan yang suci dan mulia. Kepada seluruh umat beriman, Kristus menganugerahkan imamat umum. Di samping imamat umum, Kristus menganugerahkan imamat khusus, yakni imamat ministerial sebagai pembagi karunia dan rahasia Allah. Di antara keduanya bertumbuh hubungan dialektis yang harmonis untuk pembangunan kesatuan dan misi Gereja, Tubuh Mistik Kristus. Dalam perjalanan selanjutnya refleksi dan penghargaan atas imamat tahbisan semakin menonjol. Situasi ini tidak lepas dari pengaruh budaya Romawi, paganisme dan tradisi Yahudi yang bersifat piramidalhirarkis.

Dalam ajaran dan refleksinya untuk menegaskan betapa mulia dan luhurnya martabat imam, khususnya imamat ministerial, para Bapa Gereja menekankan karakteristik dan nilai-nilai yang harus dimiliki seorang imam dalam melaksakan imamat mereka. Melalui tahbisan, para imam dihantar kepada status yang luhur sebagai alter Christus. Jati diri ini mendorong para imam untuk hidup seperti Kristus - Sang Pastor Bonus yang menempatkan keselamatan domba sebagai prioritas hidup dan reksa pastoral. Modalitas pelayanan dapat berubah sejurus dengan tuntutan zaman, namun hakikat pelayanan tetap sama. Kesaksian para Bapa Gereja tentang eksistensi dan pelayanan kaum tertahbis tetap aktual. 


\section{DAFTAR PUSTAKA}

Benedictus XVI, Bapa-bapa Gereja, Hidup, Ajaran, dan Relevansi bagi Manusia di Zaman Kini (Judul: The Fathers,. diterjemahkan oleh Waskito SJ), (Malang: Dioma), 2010.

Congregation for Catholic Education, Instruction on the Study of the Fathers of the Church in the Formation of Priests, no 17-18, (Rome: tanpa penerbit), 1989.

dal Covolo, Enrico. Sacerdoti come i nostri Padri, I Padri della Chiesa maestri di formazione sacerdotale, (Roma: Editrice Rogate), 1998.

Chrysostom, "Treatise concerning The Christian Priesthood" dalam Philip Schaff (ed), Nicene and Post Nicene Fathers, Series I, Vol. 9 (Massachusset: Hendricson Publiser), 1999, hlm. 33-83.

Drobner, Hubertus R. Patrologia, (judul asli: Lehrbuch der Patrologie, traduzione italiana di Paolo Stefano Neri e Francesco Sirleto), (Casale Monferrato: Piemme) 1998.

Grossi, Vittorino - Di Berardino, Angelo. La Chiesa antica: ecclesiologia e istituzioni, (Roma: Borla), tanpa tahun.

Kitab Didache (diterjemahkan oleh Christian P. Sidenden, John Simon Adam dan Dimitri Nugrahadi), (Jakarta: Synaxis Press), 2006.

Padovese, Luigi. I sacerdoti dei primi secoli, Testimonianze dei Padri sui ministeri ordinati, (Roma: Laurentianum), 1992.

Paolo VI, Esortazione Apostolica Evangelii Nuntiandi 73, AAS 68, Enchridion Vaticanum V (1976).

Paul II, John. Apostolic Letter Patres Ecclesiae, no. 6, AAS.72, Enchridion Vaticanum VII, (1980),

Paulus II, Yohanes, Anjuran Apostolik Pastores Dabo Vobis no. 5, (Seri Dokumen Gerejawi no. 25), diterjemahkan oleh R. Hardawiryana (Jakarta: DokPen KWI, 1992). 
Ignatius, "Epistle to Policarp" dalam Alexander Roberts - James Donaldson, Ante Nicene Fathers Vol. 1: The Apostolic Fathers with Justin Martir and Irenaeus ((Massachusset: Hendricson Publiser, 1999), hlm. 93-96.

Ignatius, "Epistle to The Ephisians" dalam Alexander Roberts - James Donaldson, Ante Nicene Fathers Vol. 1: The Apostolic Fathers with Justin Martir and Irenaeus ((Massachusset: Hendricson Publiser, 1999), hlm. 49-58.

Ignatius, "Epistle to The Magnesians" dalam Alexander Roberts - James Donaldson, Ante Nicene Fathers Vol. 1: The Apostolic Fathers with Justin Martir and Irenaeus ((Massachusset: Hendricson Publiser, 1999), hlm. 59-65.

Ignatius, "Epistle to The Trallians" dalam Alexander Roberts - James Donaldson, Ante Nicene Fathers Vol. 1: The Apostolic Fathers with Justin Martir and Irenaeus ((Massachusset: Hendricson Publiser, 1999), hlm. 66-72. 